\title{
A proposed ecosystem-based management system for marine waters: linking the theory of environmental policy to the practice of environmental management
}

\author{
$\underline{\text { Rafael Sardà }}^{1}$, Tim O'Higgins $^{2}$, Roland Cormier $^{3}$, Amy Diedrich $^{4}$ and Joaquin Tintoré $^{5,6}$
}

\begin{abstract}
New coastal and marine management strategies have recently been developed in many countries and regions. From an ecosystem approach perspective, the aim of such strategies is the maintenance of ecosystem integrity while enabling the sustainable use of ecosystem goods and services. There is, however, a need for harmonized definitions and standardized processes to deal not only with the interjurisdictional and multidisciplinary complexities that are associated with such strategies but also with the extensive timelines and resources implicated in the planning and implementation of these strategies. The ecosystem-based management system proposed here is based on three pillars that facilitate the integration of an ecosystem approach to coastal and oceans policy development, regardless of the ecosystem or administrative scales. The managerial pillar is based on classical risk-management systems that incorporate environmental considerations and objectives within a continuous improvement cycle of adaptive management. The managerial pillar is supported by governance structures that provide oversight and thereby ensure that planning and implementation activities adhere to modern environmental principles. The information pillar ensures that data and scientific advice are based on current knowledge, and the participation pillar brings together communication and consultation requirements as indicated by the principles of the ecosystem approach.
\end{abstract}

Key Words: ecosystem approach; ecosystem-based management; ecosystem goods and services; environmental management; marine environment; marine ecosystems; marine management strategy; oceans policy

\section{INTRODUCTION}

Internationally, the ecosystem approach (EA) has emerged as the dominant paradigm for managing marine ecosystems (Borja et al. 2008, Olsen et al. 2009, Espinosa-Romero et al. 2011). The ecosystem approach - "a resource planning and management approach that integrates the connections between land, air and water and all living things, including people, their activities and institutions" (Farmer et al. 2012) - aims to protect the health, productivity, and resilience of these ecosystems as well as the ecosystem goods and services valued by human beings (McLeod et al. 2005, Rice et al. 2005, Borja et al. 2008, McLeod and Leslie 2009, Mengerink et al. 2009). In Europe, the recently introduced Marine Strategy Framework Directive (MSFD) (European Commission 2008) seeks to implement the ecosystem approach into marine management. Its purpose is to protect marine ecosystems while at the same time recognize society's need to benefit from marine resources in a sustainable manner (Elliott 20101, Farmer et al. 2012, Ounanian et al. 2012). The Marine Strategy Framework Directive represents a major challenge for countries because it requires transposition of policy from the international level to the national and local levels (Mee et al. 2008). Member States implementing the Marine Strategy Framework Directive are subjected to different levels of institutional ambiguity and are required to cooperate and coordinate at the regional level in an effective system of multilevel governance (van Leeuwen et al. 2012). Appropriate tools, governance systems, and networks, are required in order to guide implementation of the ecosystem approach, whether in Europe through the Marine Strategy Framework Directive or internationally through other policies.
The ecosystem approach has many names, it is widely considered synonymous with the ecosystem-based approach (EBA) or ecosystem-based management (EBM). A variety of guidelines and compendia offering a broad range of new governance mechanisms and tools have been developed to facilitate implementation of the ecosystem approach (Shepherd 2008, Ehler and Douvere 2009, Mengerink et al. 2009, Roxburgh 2012). One emerging tool is marine (or maritime) spatial planning (MSP) (Douvere 2008, Douvere and Ehler 2009, Katsanevakis et al. 2011) and the related ecosystem-based marine spatial management (EB-MSM). However, the growing number of guidance documents and the preponderance of jargon (EA, EBA, EBM, marine/maritime SP, EB-MSM) describing similar or interrelated concepts can be confusing and can make the ecosystem approach seem nebulous, rendering it difficult to put into practice. In addition, current governance systems and policy outcomes are fragmented and complex, lack transparency and are often reactive rather than proactive (Cormier et al. 2010, Bainbridge et al. 2011). As a consequence, management of individual sectors within the marine environment remains the norm and, though widely discussed in academic circles, the ecosystem approach is rarely applied in practice (Katsanevakis et al. 2011).

There are many examples of this gap between theory and practice (Arkema et al. 2006, Ruckelhaus et al. 2008, Tallis et al. 2010, Curtin and Prellezo 2010, Espinosa-Romero et al. 2011, Katsanevakis et al. 2011) which may be compounded by different interpretations of the ecosystem approach in different countries (Arkema et al. 2006, Aswani et al. 2012). Several major obstacles have been identified, including the lack of common visions and

${ }^{1}$ Consejo Superior de Investigaciones Científicas, Centro de Estudios Avanzados de Blanes (CSIC-CEAB), Spain, ${ }^{2}$ Scottish Association for Marine Science (SAMS), Scottish Marine Institute, Scotland, ${ }^{3}$ Gulf Fisheries Centre, Fisheries and Oceans Canada, ${ }^{4}$ School of Earth and Environmental Sciences, James Cook University, Australia, ${ }^{5}$ Sistema d'Observació I Predicció Costaner de les Illes Balears (SOCIB), Spain, ${ }^{6}$ Consejo Superior de Investigaciones Científicas, Instituto Mediterráneo de Estudios Avanzados (CSIC-IMEDEA), Spain 
objectives, the lack of proper governance frameworks, the need to establish a systems perspective, and the confusing array of terminology. In order to implement the ecosystem approach, the theory of ecosystem science must be reconciled with the practice of ecosystem management (deReynier et al. 2010).

Management is about making decisions to reach a desired state. Management of environmental public goods, including ecosystem goods and services, therefore, is about making the best decisions for societies, preserving the functional integrity of natural systems, and maintaining the provision of their goods and services. In Europe, according to the Marine Strategy Framework Directive (European Commission 2008), management of the marine environment should be based on a "process" intended to reach and/or maintain Good Environmental Status (GEnS) by applying ecosystem approach principles (Borja et al. 2010, 2013). Given that public goods, are different in nature from private goods and that an ecosystem approach requires public participation in the management of public goods, it follows that a new set of management practices is needed to implement this new approach.

Our aim is to define a standardized process for applying ecosystem approach principles by ensuring the inclusion of essential components such as participation, planning, and decision making, and by promoting accountability and quality assurance to achieve management objectives that follow sustainable development principles and are based on ecosystem services (Government of the Netherlands and Government of Malawi 1998, Balvanera et al. 2001, Cognetti and Maltagliati 2010). Standards, guidelines, and quality-assurance systems are widely used in industry and many fields of management to ensure quality and accountability. We present a structured process (or standard operating procedure) called the ecosystem-based management system (EBMS) to implement the ecosystem approach. The ecosystem-based management system is a quality-assurance, adaptive-management tool that introduces the ecosystem approach into practice by normalizing a common set of tools and introducing a common language that are particularly useful for practice and capacity building. The ecosystem-based management system combines classical environmental and riskmanagement system theory (Measham and Lockie 2012) with the principles of an ecosystem approach (Government of the Netherlands and Government of Malawi 1998, Farmer et al. 2012) in order to develop a formal systematic structure for adaptive management of marine public goods. The ecosystembased management system could be applied anywhere but in the European context it has clear potential for harmonization of the Marine Strategy Framework Directive. Here we use the example of the Marine Strategy Framework Directive as a context for the application of the ecosystem-based management system, we illustrate how elements of the ecosystem-based management system could be operationalized using examples based on Canadian experiences with Canada's Ocean Act implementation, a model that is exportable to other places (Jessen 2011).

The paper is structured as follows: in the next section we describe the components of the ecosystem-based management system, including tools and practices that are recommended to be implemented in different parts of the system. In the subsequent sections we discuss individual components of the ecosystembased management system that are already found in the Canadian experience and insights into how the ecosystem-based management system could facilitate the implementation of the marine strategies in Europe. Finally, we discuss the advantages of the ecosystem-based management system over existing models and present some concluding remarks.

\section{ECOSYSTEM-BASED MANAGEMENT SYSTEM}

\section{Overview}

The ecosystem-based management system has a three-pillar structure (Fig. 1). The managerial pillar is the basis of the system and follows a formal classical environmental management system (EMS) which incorporates a risk-management system (RMS). The information and the participatory pillars provide the ecological and social inputs in terms of scientific data and the social preferences required to support and operate the ecosystembased management system and achieve social/ecological targets under an ecosystem approach. For clarity the ecosystem-based management system employs the driver-pressure-state-welfareresponse (DPSWR) social-ecological accounting framework for organizing the information on aspects of social and ecological systems relevant to representing the interactions between them (Cooper 2013).

Under the Marine Strategy Framework Directive, the final objective is to reach and/or to maintain GEnS; this also represents the goal or vision for which the ecosystem-based management system is used to achieve. In order to develop the roadmap to reach this vision, an Initial Assessment describing the baseline conditions for the specific social-ecological system should be carried out. The Initial Assessment should contain all available relevant information needed to understand the functioning of the area under management, including an analysis of human activities (drivers) that lead to exogenic and endogenic pressures (Elliott 2011) and their effects on the current environmental state of the ecosystem. The results of the Initial Assessment represent the point of departure for the social-ecological system under management. The final desired vision for the managed area (GEnS in the case of the Marine Strategy Framework Directive) represents the targeted "state" of the social-ecological system under management. By reaching and/or maintaining such a vision, an acceptable set of pressures can be allocated under certain ecological, technical, behavioral, administrative, and managerial constraints.

The actions carried out as part of the ecosystem-based management system represent a "response" which is dependent on the presence of an effective governance structure which can uphold the modern principles of environmental management (Olsen et al. 2009). This requires a committed leadership (a constituent organ or physical person) with a public mandate, as well as the active participation of stakeholders.

\section{Managerial pillar}

The Managerial pillar is the "engine" of the ecosystem-based management system. It maps a framework to set up an effective management system for reaching and maintaining particular targets and is based on a formal environmental management system (EMS). The managerial pillar operates on the policy cycle assessment developed inter alia by the Joint Group of Experts on the Scientific Aspects of Marine Environmental Protection (GESAMP 1996) and follows the classical plan-do-check-act managerial policy scheme (Deming 1986). It is an iterative, continuous, quality-improvement model consisting of a logical 
Fig. 1. General structure of the ecosystem-based management system= (right), showing one of the cycles in the adaptive management process (left). Steps in the process (indicated by white text boxes) are discussed in the text. (GEnS = Good Environmental Status)

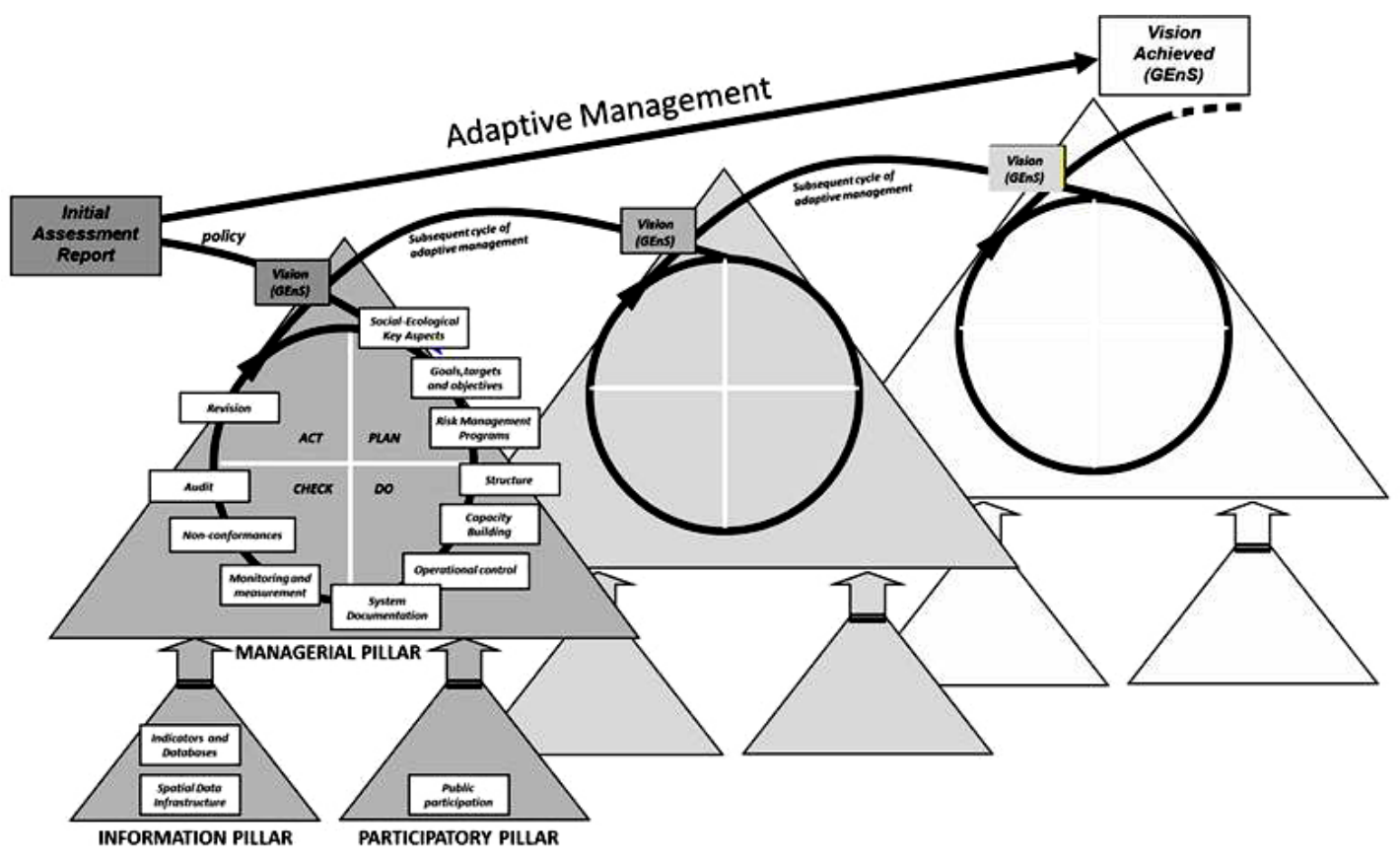

sequence of four repetitive steps, which can adapt to changes in the system under management. In the ecosystem-based management system, the iterative steps of the system follow the International Organization for Standardization's frameworks for environmental and risk management, i.e., ISO 14001 (ISO 2004) and ISO 31000 (ISO 2009a; 2009b; 2009c). The inclusion of a risk-management standard follows modern management best practices for environmental decision making (MacDiarmid 1997, Cormier et al. 2013) while the use of an environmental management system is a well-established tool for achieving environmental targets. The structure of the managerial pillar and its relation to environmental management system/riskmanagement system frameworks is shown in Fig. 2. The managerial pillar of the ecosystem-based management system is the piece of management that guides the user toward the desired vision over time through the completion of adaptive management cycles.

In the following sections we provide details about the specific content of the elements shown in Fig. 2. A more detailed explanation of the ecosystem-based management system managerial pillar and its clauses can be seen at KnowSeas' web portal (http://www.msfd.eu).

General structure and vision

The ecosystem-based management system is a vision-driven process. The vision establishes the goals and time scales for environmental performance against which the effectiveness of the management system will be judged. The goals should be quantitative, clear, and verifiable, and should be linked to outcomes. These can be adapted if necessary as more scientific knowledge is obtained. A competent authority should be designated, by mandate, to set up and run the system in terms of legislative and policy accountability. The designated authority should form part of an effective governance system. Prior to implementing the ecosystem-based management system, the competent authority, governance members, and stakeholders should fully understand the ecosystem-based management system and agree how it is to be implemented in decision making.

\section{Planning phase (plan)}

Following determination of the "status quo" (in the Initial Assessment) and the "targeted state" through establishing a vision (GEnS in the Marine Strategy Framework Directive) and having put in place a general structure to progress towards this vision, the ecosystem-based management system enters the planning phase. The aim of the planning phase is the selection of a series of prioritized actions for progress toward the desired vision. The planning phase is structured in four formal clauses following a risk-management system framework (the risk-Assessment phase of the new ISO 31000:2009 (ISO 2009c)):

A.3.1. National and International requirements. The competent authority shall establish and maintain a procedure to identify all National and International requirements under which the area/region under management has obligations.

A.3.2. Social-Ecological key aspects. The competent authority shall establish and maintain a procedure to identify aspects (human activities, events or hazards) that may have an influence on achieving the vision for the site under management.

A.3.3. Risk-Management Plan. The competent authority shall establish and maintain the documented Plan, with its objectives and targets. The Plan is the latest document based on the riskassessment approach. 
Fig. 2. Managerial pillar of the ecosystem-based management system, showing the different phases of management. Those clauses marked with an asterisk differ from the ISO 14001 environmental management system.

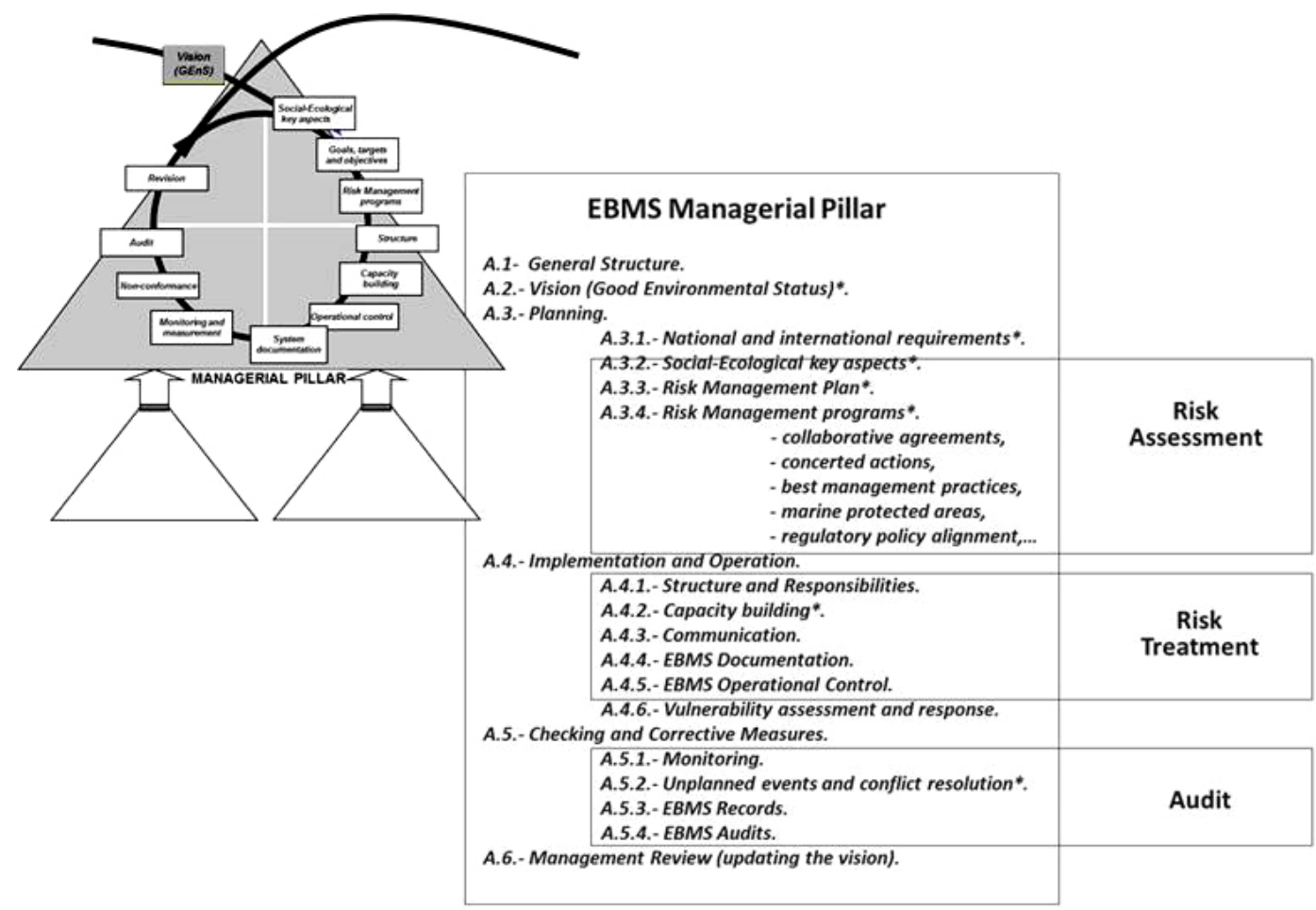

A.3.4. Risk-Management Programs. The competent authority shall establish and maintain a series of risk-management programmes and procedures intended for each management period upon which audits and reviews would be carried out.

Key risks to different components of ecosystem state are evaluated following the risk identification-risk analysis-risk evaluation scheme (Cormier et al. 2013), and a decision-support mechanism is used to prioritize and select operational objectives inside the management plan. For the decision-support mechanism, the ecosystem-based management system proposes to use a special tool called DEMA (for DEcision MAking) at the beginning of the planning phase. Supplementary material about the DEMA tool can be seen at KnowSeas' web portal (http://www. msfd.eu).

\section{Implementation phase (do)}

The implementation phase, during which the management plans that are designed and agreed upon in the planning phase are put into practice, is described in six formal clauses:

A.4.1. Structure and responsibilities. Roles, responsibilities and authorities shall be defined, documented and communicated in order to facilitate effective management.

A.4.2. Capacity building. The competent authority shall identify training needs.

A.4.3. Communication. A risk-management communication plan should be implemented. Internal risk-management communication and reporting processes as well as external communication plans must be established.

A.4.4. Ecosystem-based management system Documentation. The competent authority should maintain the programmes needed to achieve its objectives and targets.

A.4.5. Ecosystem-based management system Operational Control. The competent authority shall identify those operations and activities associated with the identified socialecological key aspects in line with its policy, objectives and targets.

A.4.6. Vulnerable assessment and response. The competent authority shall establish and maintain procedures to identify potential for and respond to accidents and emergencies, as well as for preventing and mitigating the environmental impacts that may be associated with them.

Two elements are particularly important for ensuring the successful application of the implementation and operation stage: the capacity and responsibilities of the personnel in charge, and the operational control of the activities (i.e., monitoring of program effectiveness).

Because stakeholder participation is a prerequisite in ecosystem approach frameworks, inclusion of stakeholders in decision making is important here. The competent authority should ensure inclusivity by making use of appropriate tools such as those described in the participatory pillar below. At this level, the competent authority should: 
1. Define roles and responsibilities and provide essential resources for the ecosystem-based management system. Resources shall include human resources and specialized skills, technology, and financial resources.

2. Ensure that all relevant stakeholders and managers understand the ecosystem-based management system and are aware that a particular site is managed under the ecosystem-based management system.

3. Implement a communication plan to facilitate internal processes as well as consultation with stakeholders.

4. Establish formal requirements for operational control and documentation of planned activities.

\section{Checking and corrective measure phase (check)}

The checking-and-corrective-action stage is based on the development of compliance-monitoring programs, including monitoring of program activities, compliance verification, and audits. The implementation phase is structured in four formal clauses:

A.5.1. Monitoring. The competent authority shall establish and maintain documented procedures to monitor and measure on a regular basis, the key social-ecological aspects that have a significant impact on the environment.

A.5.2. Unplanned events and conflict resolution capacity. The competent authority shall establish an alert system to detect inappropriate functioning in the system and/or unexpected environmental hazards/activities.

A.5.3. Ecosystem-based management system records. The competent authority shall establish and maintain procedures for the identification, maintenance and disposition of socialecological key records used in the system as well as the evaluation of the indicators selected for the desired vision.

A.5.4. Ecosystem-based management system audits. The competent authority shall establish and maintain a program and procedures for periodic system audits to be carried out.

Although the ecosystem-based management system can be considered a quality-assurance tool in itself, the audit clause is an important internal quality-assurance mechanism. At this stage, the management system should be able to assess the level of conformity of the programs in the management plan and the effectiveness of these programs in achieving the vision for the system.

Monitoring programs in the ecosystem-based management system framework should also act as regulatory compliancesurveillance mechanisms as well as be aligned with any other existing marine conservation agreements or commitments such as collaborative management activities and sectorial plans and their associated monitoring efforts (e.g., Nature Conservancy, http://mcatoolkit.org).

An audit process or quality-assurance mechanism needs to be included in each management cycle of the system in order to determine: (a) whether or not the ecosystem-based management system conforms to planned arrangements for the socialecological system management, including the requirements of this standard system, and (b) whether or not the ecosystem-based management system has been properly implemented and maintained. The audit must provide information on the results of audits to management. The audit should determine the level of conformity in attaining objectives as well as the effectiveness of actions in meeting environmental targets.

Reviewing phase (act)

The management review is an essential part of the continual improvement of a management system. To operate within the principles of adaptive management, periodic reviews to develop new plans and new implementation programs are necessary as new developments occur. In this way the ecosystem-based management system can adapt due to the presence of feedback loops. The vision for the system is re-analyzed as part of this review, and the distance from the objective (GEnS in a European context) is assessed at this time based on program performance during the previous cycle. The review is connected with the planning phase of the next cycle. Making use of the riskmanagement tool (in the planning phase above), the revision needs to establish the external and internal contexts in which the next identification and prioritization of programs should be conducted. The suitability, adequacy, and effectiveness of the entire process are also evaluated at this time. The process should ensure that the necessary information is collected to allow management to carry out this evaluation.

While the structure and processes of the managerial pillar described above are relatively simple, they cannot operate in isolation. The information and participation pillars of the ecosystem-based management system provide the essential scientific data, and the participatory inputs for running the system. Both are critical aspects for managing decisions in the system.

\section{Information pillar}

The information pillar of the ecosystem-based management system provides the risk-assessment and decision-making components of the managerial pillar with data to inform the decision-making process. Because spatial data are essential to implementation of the ecosystem approach, some form of spatial data infrastructure (SDI) (Cinnirella et al. 2012) is required. The relevant properties and processes (and related data) often occur at different spatial scales and may be under different ownership in different jurisdictions: for example, the local scale vs. a riverbasin scale, or the national scale vs. a regional sea scale. The necessity for spatial data in the ecosystem approach and the problems of spatial data are recognized within Europe (European Commission 2007). The spatial data infrastructure required to provide this geodata is beginning to emerge in Europe (e.g., European Marine Observation and Data Network). Once an established and reliable network of this type is in place, availability of data will become less of a constraint on ecosystem approach implementation.

Spatial modelling and mapping of social-ecological data using the driver-pressure-state-welfare-response conceptual frame (Cooper 2013) in a particular location can provide the basis for informed decision making (Cinnirella et al.2012). Fig. 3 illustrates an example of an spatial data infrastructure structure specifically designed to support Marine Strategy Framework Directive implementation using the ecosystem-based management system. 
Fig. 3. Example of the spatial data infrastructure required to support the ecosystem-based management system. $($ OGC $=$ Open Geospatial Consortium. WMS $=$ Web Map Server. WCS $=$ Web Coverage Server. WFS $=$ Web Feature Server)

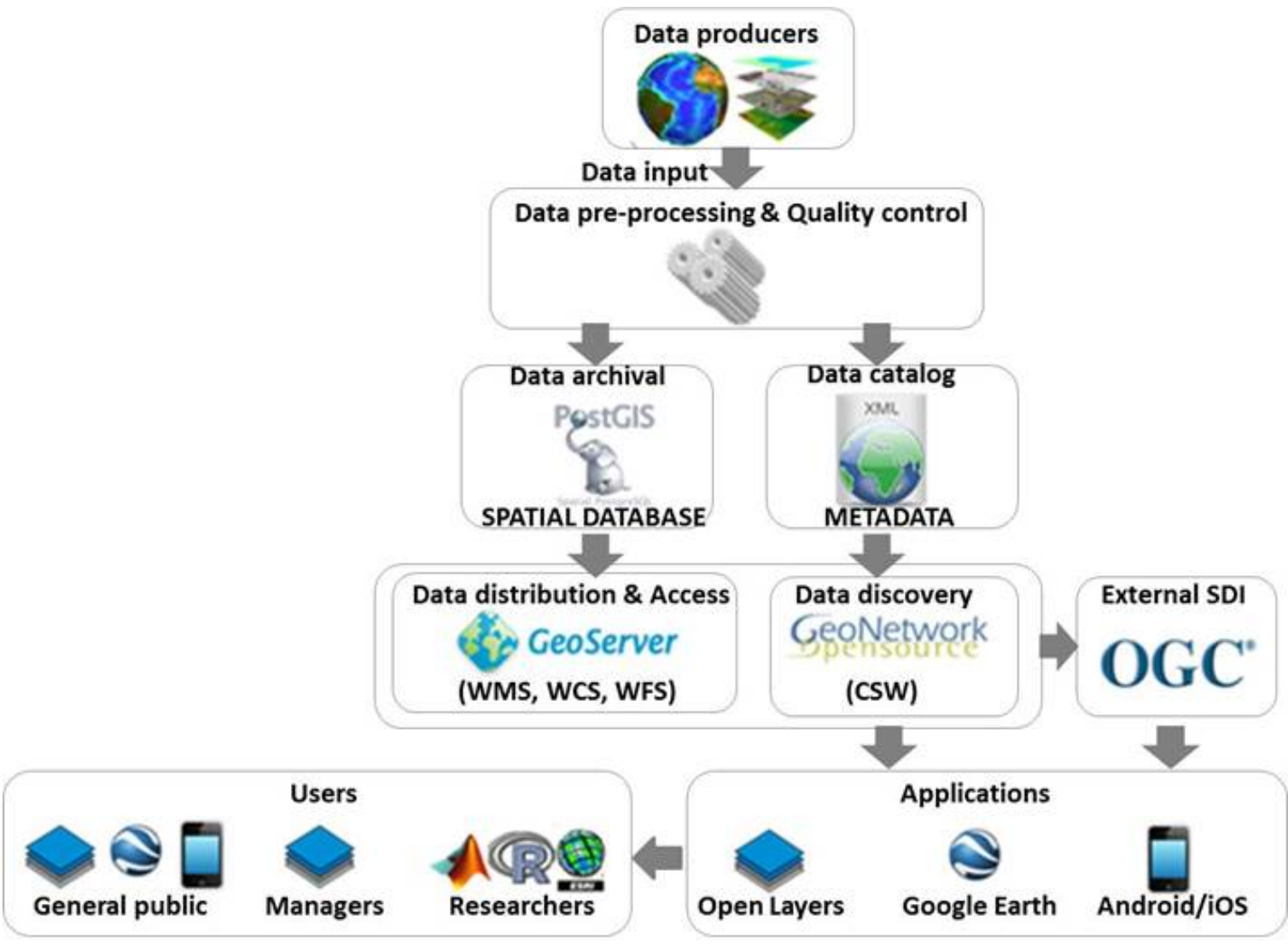

This spatial data infrastructure is compliant with European Union data standards (European Commission 2007); uses open source software, GeoServer, and Geonetwork to accommodate data access distribution and discovery in a range of interchangeable data formats; and is described in more detail in Cinnirella et al. (2012). An application to a particular case study with data from the Gulf of Lions (northwestern Mediterranean) can be accessed online (http://knowseas. socib.es/lion/composer/). This application follows another recommended tool, named GISSeas. The GIS-Seas is an analytical and visualization tool intended to provide real-time information for decision making using data standards commented on above. (Supplementary material about the GIS-Seas tool can be found using KnowSeas' GIS tool at http://knowseas.socib.es/lion/composer/ or at KnowSeas' web portal at http://www.msfd.eu)

\section{Participatory pillar}

The ecosystem approach should be a multisectorial process that includes the participation of stakeholders (Tallis 2010). Participation requires active involvement of the actors (people influencing and affected by management actions). For the ecosystem approach to be truly effective it must be supported by and include all levels of society, sectors, and stakeholders throughout the implementation of the ecosystem-based management system. However, at present, levels of public understanding about the marine environment (at least in Europe) are very low (Rose et al. 2008, Potts et al. 2011) and not all actors have the same degree of organization, education, or capacity to participate.

The participatory pillar of the ecosystem-based management system is included in order to ensure that communication occurs with stakeholders, and to build capacity of the public to participate. The ecosystem-based management system can only be effective if it is understood by all concerned stakeholders. Within Europe, tools are available for the identification of stakeholders (e.g. Sanó 2009, Bainbridge et al. 2011), and initiatives to generate informed networks of stakeholders are beginning to emerge both at the institutional level through the International Council for the Exploration of the Seas (ICES) Regional Advisory Councils, which are comprised of members from different marine sectors, as well as through grassroots movements in order to encourage wider public participation (e.g., Roxburgh 2012). Fundamental to the inclusivity of the process is the availability of information about the ecosystem approach. To this end we have developed a web portal for the purpose of enhancing stakeholder capacity. KnowSeas' web portal (http://www.msfd.eu) contains materials, including videos, guidelines, and policy briefs (as well as a section explain the ecosystem-based management system). This portal is designed to explain the ecosystem approach and its relevance to the general 
public, policy makers, and managers at European Union, national, and local levels, and to explain the legal obligations for European member states under the Marine Strategy Framework Directive.

\section{POTENTIAL APPLICATIONS}

While the structured process of an ecosystem-based management system has not been formally put into practice, many of the elements that contribute to the structure are emerging as regulators are gaining practical experience with the ecosystem approach. The formalized structure presented above may provide the basis for a more widely applied standard approach. Below, we describe how elements of the ecosystem-based management system can be found in some tools used in the management of Canadian waters and how the ecosystem-based management system application could facilitate the management of European waters.

\section{Canada}

In Canada, marine planning is conducted under the authorities of the Oceans Act (1996) which provides a mandate for an integrated approach to the management of human activities. Accountability for marine human activities lies within the jurisdiction of federal and provincial authorities that regulate the sectors operating within the marine management area. Oceans management integrates multijurisdictional requirements in the planning process, incorporating ecosystem and socioeconomic considerations within the frame of an ecosystem-based management approach (Fisheries and Oceans Canada 2002).

Several elements of the ecosystem-based management system proposed here could also be seen in relation to the experience of the Canadian authorities (Table 1). The elements of the managerial pillar are addressed by the governance structure that is implemented for each large ocean management area. The elements of the participatory pillar are addressed through stakeholder and public engagement, while the elements of the information pillar are addressed through institutional data and information management requirements and scientific advisory processes.

Parts of the ecosystem-based management system managerial and information pillar can be recognized in the basic elements used to manage Canadian waters. Guidelines are used by authorities to ensure consistency in the implementation of policies and advisory processes (Table 1). Canadian scientific advisory processes involve stakeholders; and the documents, published publicly, are the formal for scientific policy inputs for program policies and directives. A repository for all these documents is kept at the Canadian Science Advisory Secretariat. The advisory processes formulate policy advice through data analysis, literature reviews, and expert knowledge. They provide the policy and technical basis for the planning processes, thus ensuring due process and due diligence within a legislative decision-making framework. Further details of the elements in the Canadian process are as follows.

Ecosystem overview and socioeconomic overview reports: These are comprehensive descriptions of the current knowledge of ecological, cultural, social, and economic considerations for the planning area.
Significant ecological areas, species, and community properties: These represent ecosystem components and services of high ecological or biological significance for which a greater-thanusual degree of risk aversion in management of activities is required. Based on vulnerabilities to specific pressures, the guidelines identify the pressures and drivers that will be included in the planning initiative.

Conservation objectives: These are established to provide a tiered priority level for the ecological and biological components and services established earlier. The conservation objectives use language that directly corresponds to the language of policies, regulations, and legislation, to guide management in the decision-making processes.

Ecosystem priorities and vulnerabilities: Risk-management frameworks are used to set ecosystem priorities and vulnerabilities (Treasury Board of Canada Secretariat 2004). Although several risk-assessment and management frameworks may be used, the rating of the risks in terms of likelihood and severity are based on standardized risk criteria. Risk criteria are used to define and classify the severity of the consequences or impacts during the risk-analysis and risk-evaluation steps of the planning processes. Risk criteria introduce the references used in making a judgement in order to determine what risks are tolerable for all parties involved in the planning process.

Regional oceans committees: In collaboration with other jurisdictions and stakeholders, the vision and objectives of the integrated oceans management plan is developed in relation to the sustainable development needs of the area. The entire process is overseen by a regional oceans committee, and it includes stakeholder-related issues to specific management issues.

Objectives and environmental quality measures: The development of the integrated management plan results in spatial and temporal management measures that take into account the regulatory requirements of the various sectors of operations. They include ecological and socioeconomic objectives or environmental quality measures.

Plan and management measures: The plan is then endorsed by the governance structures and implemented by the decisionmaking authorities. Documentation is provided by the published plans and management measures.

Monitoring and measuring: Ongoing environmental monitoring activities are then used to provide insight into the status and trends of ecological indicators. Although it may be difficult to tie the status and trends of the ecological indicators to specific management measures, the resulting report sets the ecological basis for all future revisions. Recently, the Global Ocean Commission provided an overview of the trends and status of the oceans (Global Ocean Commission 2014).

Auditing standards and guidelines: Based on the legislative authorities of the management measures, each competent authority conducts compliance-verification activities that are in line with the enforcement requirements of their respective acts and regulations (Canadian Environmental Assessment Act, 2012). Program and performance audits are undertaken to ascertain if the plan is being implemented adequately or if 
Table 1. Steps in the integrated management process and documents used by Canadian authorities in relation to the elements of the ecosystem-based management system.

\begin{tabular}{l}
\hline \hline $\begin{array}{l}\text { Steps in the integrated } \\
\text { management process }\end{array} \quad$ Science policy advice: Canadian documents \\
system: clauses and tools
\end{tabular}

\begin{abstract}
Ecosystem and socioeconomic overview report

Fisheries and Oceans Canada. 2005. Guidelines on evaluating ecosystem overviews and assessments: necessary documentation. Science Advisory Report 2005/026. Fisheries and Oceans Canada, and Canadian Science Advisory Secretariat, Ottawa, Ontario, Canada.

Fisheries and Oceans Canada. 2011. Social, economic, and cultural overview of the Quebec Region. Oceans, Habitat and Species at Risk Publication Series, Newfoundland and Labrador Region No. 0007. Newfoundland and Labrador Region, St. John's, Newfoundland, Canada.
\end{abstract}

Fisheries and Oceans Canada. 2011. Social, economic and cultural overview of western Newfoundland and southern Labrador. Oceans, Habitat and Species at Risk Publication Series, Newfoundland and Labrador Region No. 0008. Newfoundland and Labrador Region, St. John's, Newfoundland, Canada.

Fisheries and Oceans Canada. 2011. Synopsis of the social, economic, and cultural overview of the Gulf of St. Lawrence. Oceans, Habitat and Species at Risk Publication Series, Newfoundland and Labrador Region No. 0005. Newfoundland and Labrador Region, St. John's, Newfoundland, Canada

Significant ecological areas, species, and community properties

Conservation objectives

Ecosystem priorities and vulnerabilities priorities for ecosystem-based oceans management in the Pacific Region. Canadian
Fisheries and Oceans Canada. 2004. Identification of ecologically and biologically significant areas. Science Advisory Secretariat, Ecosystem Status Report 2004/006. Ottawa, Ontario, Canada.

Fisheries and Oceans Canada. 2006. Identification of ecologically significant species and community properties. Science Advisory Secretariat, Science Advisory Report 2006/041. Ottawa, Ontario, Canada.

Fisheries and Oceans Canada. 2009. Does eelgrass (Zostera marina) meet the criteria as an ecologically significant species? Science Advisory Secretariat, Science Advisory Report 2009/018. Ottawa, Ontario, Canada.

Fisheries and Oceans Canada. 2012. Definitions of harmful alteration, disruption or destruction (HADD) of habitat provided by eelgrass (Zostera marina). Canadian Science Advisory Secretariat, Science Advisory Report 2011/058. Ottawa, Ontario Canada.

Fisheries and Oceans Canada. 2007. Guidance document on identifying conservation priorities and phrasing conservation objectives for large ocean management areas. Canadian Science Advisory Secretariat, Science Advisory Report 2007/010. Ottawa, Ontario, Canada.

Fisheries and Oceans Canada. 2009. Conservation objectives for the Ecologically and Biologically Significant Areas (EBSA) of the Estuary and Gulf of St. Lawrence. Canadian Science Advisory Secretariat, Science Advisory Report 2009/049. Ottawa, Ontario, Canada.

Fisheries and Oceans Canada. 2012. Risk-based assessment framework to identify Science Advisory Secretariat, Science Advisory Report 2012/044. Ottawa, Ontario, Canada.

Treasury Board of Canada Secretariat. 2010. Framework for the management of risk Ottawa, Ontario, Canada.

International Organization for Standardization (ISO). 2009. ISO 31000:2009, risk management-principles and guidelines. Geneva, Switzerland.

International Organization for Standardization (ISO). 2009. IEC 31010:2009, risk management-risk assessment techniques. Geneva, Switzerland.
Initial assessment report (managerial pillar)

Social/ecological key aspects (managerial pillar)

Goals, targets, and objectives

Risk-management program (managerial pillar) 
Regional oceans committees

Objectives and environmental quality measures

Plan and management measures

Monitoring and measurement

Auditing standards and guidelines
Oceans Directorate. 2002. Canada's oceans strategy: our oceans, our future-policy and operational framework for integrated management of estuarine, coastal and marine environments in Canada. Cat. No. Fs77-2/2002E. Fisheries and Oceans Canada, Ottawa, Ontario, Canada.

Oceans Directorate. 2008. The role of the Canadian Government in the oceans sector. DFO/2008-1515. Cat. No. Fs23-319. Fisheries and Oceans Canada, Ottawa, Ontario, Canada.

Oceans Directorate. 2008. The role of the Provincial and Territorial Governments in the oceans sector. DFO/2008-1494. Cat. No. Fs23-319. Fisheries and Oceans Canada, Ottawa, Ontario, Canada.

Oceans and Habitat Branch. 2007. Eastern Scotian Shelf Integrated Ocean Management Plan: strategic plan. DFO/2007-1229. Cat. No. Fs23-512/1-2007E. Fisheries and Oceans Canada, Dartmouth, Nova Scotia, Canada.

Beaufort Sea Partnership. 2009. Integrated Ocean Management Plan for the Beaufort Sea: 2009 and beyond. Beaufort Sea Planning Office, Inuvik, Northwest Territories, Canada.

Centre of Expertise on the State of the Oceans. 2012. Canada's state of the oceans report, 2012. DFO/2012-1818. Fisheries and Oceans Canada, Ottawa, Ontario, Canada.

Centre of Excellence on Risk Management. 2014. Guide to integrated risk management: a recommended approach for developing a corporate risk profile. Treasury Board of Canada Secretariat, Ottawa, Ontario, Canada. [online] URL: http://www.tbs-sct.gc.ca/ tbs-sct/rm-gr/guides/girm-ggirpr-eng.asp

International Organization for Standardization. 2006. ISO/IEC 17021:2011, conformity assessment -requirements for bodies providing audit and certification of management systems. Geneva, Switzerland.

Office of the Auditor General of Canada. 2004. Performance audit manual. Ottawa, Ontario, Canada. [online] URL: http://www.oag-bvg.gc.ca/internet/methodology/ performance-audit/manual/index.shtm

Information management
Fisheries and Oceans Canada. 2003. Guide for the production of Fisheries and Oceans Canada reports. Revised 07/05/2014. Ottawa, Ontario, Canada. [online] URL: http:// www.dfo-mpo.gc.ca/Library/333125.pdf
Structure (managerial pillar)

Operational control (managerial pillar)

System documentation (managerial pillar)

Monitoring and measurement (managerial pillar)

Nonconformance and auditing (managerial pillar)

Spatial data infrastructure (information pillar) the management measures are effective in achieving the goals and objectives. An audit provides verifiable evidence and reproducible results by following a systematic process to gather information that is analyzed against pre-established conformity criteria. In cases where nonconformities are found, corrective actions are implemented. Nonconformities are deviations from a management measure specification or standard that may result in the plan not achieving the established goals or objectives. It can also be a deviation from a procedural perspective stipulated by the planning process. The scope of auditing activities may also include mandate or program implementation to review the performance of the institutions and processes in the administration of the plan. As with environmental monitoring, compliance verifications and audits are key pieces of information for the review. From the governance perspective, compliance verifications and audits are used to provide evidence as to the performance of the management plan in meeting legislative requirements and ecosystem objectives. From the stakeholder's perspective, these also provide the basis for determining the feasibility of the implemented management measures.

Revision: Depending of the legislative requirements, plans may be implemented for fixed time frames. Prior to reaching the plan's review date the planning process restarts, thus bringing new knowledge and monitoring information into the review. The review is also conducted under the same governance and public engagement structure as the initial planning initiative. It should be noted that the information provided by environmental monitoring activities, compliance verifications, and auditing activities are key elements to be considered in the review.

Information management: The Canadian Scientific Advisory Secretariat manages peer-review processes that are conducted to address scientific questions that may emerge during the planning process. The intent of these processes is to ensure quality, objectivity and inclusiveness of the policy advice. In addition to the advisory documents, research documents documenting the data, methods, and results are produced for every aspect that was included in the formulation of the advice. They are also available to the public via the Internet. Where preliminary analysis is needed, workshop proceedings are also prepared as part of a multi-iterative process that will lead to the advice.

The Canadian experience in the application of the ecosystem approach to the management of its marine waters yielded a series of widely used tools, procedures, and guidance documents. Using 
these elements, bottom-up (action-based) approaches and topdown (ecosystem-property-based) approaches were developed and tested. As Jessen (2011) suggested, the Canadian example of ocean management is widely held to be a successful example of the ecosystem approach. This system has developed within the unique jurisdictional context of the country itself. As illustrated above, the structure of the ecosystem-based management system incorporates the essential elements of the Canadian process. Including all these elements into a standard system could reinforce all these procedures and could stimulate the revision of the entire process through a continuous improvement vision, thereby facilitating a wider dissemination and serving as example for the entire world in practicing the ecosystem approach.

\section{Europe}

The marine policy agenda in Europe is the result of the European Integrated Maritime Strategy (Juda 2007). The strategy is moving forward as a result of both the European Marine Strategy Framework Directive (European Commission 2008) for preserving the integrity of the seas, and the use of maritime spatial planning for planning and maritime development, as well as because of the reform of the Common Fisheries Policy (European Commission 2009). These strategic twin pillars of sustainability and growth have resulted in a mandate for management platforms to guarantee policy implementation.

In the European Union there have been major efforts to encourage the practice of an ecosystem approach; a large number of projects across different programs have tried to bring the ecosystem approach principles into practice using a myriad of tools for their application. For example, elements of the information pillar in the ecosystem-based management system are already in place; spatial data are increasingly available through initiatives such the European Marine Observation and Data Network (EMODNET), and, stimulated by the Commission's green paper on spatial data infrastructure (European Commission 2012). are beginning to provide the information that would be required for the riskassessment and planning phase of the ecosystem-based management system. The participatory pillar is also reasonably well developed. Networks of stakeholders and interest groups are beginning to develop (e.g., Roxburgh 2012) and participate in the Marine Strategy Framework Directive process, and the structures of the existing regional seas agreements (OSPAR in the North Sea and HELCOM for the Baltic) are also being harnessed. However, the degree of public understanding of the marine environment and the problems facing it (Rose et al. 2008, Potts et al. 2011) suggest that there is still a great need for capacity building and education. In this case, a common system of management would facilitate communication across Europe.

However, while the Canadian situation imposed a federal mandate under its Oceans Act, within Europe the implementation of the Marine Strategy Framework Directive and the marine spatial planning, and the practice of the ecosystem approach, require transcription into national legislation. Comprised of 28 different countries, each with their own unique institutional histories and cultures, policy fragmentation represents a major challenge to coherent implementation of the policy at regional scales. By the adoption of an inclusive management structure such as the ecosystem-based management system, current management systems could benefit from a common language and a common methodology for implementing solutions to this challenge.

The adoption of a standard such as the ecosystem-based management system could provide a benchmark of the formal structures and the iterative systems required to achieve an ecosystem approach. It also could provide a coherent set of instructions for managers to follow while incorporating the differences in institutional culture and national practices that are inherent in the European Union. The ecosystem-based management system also could allow individual nations the flexibility to use existing tools, i.e., those already developed or in use but under the same general management framework as other member states. For Europe the potential strength of the ecosystem-based management system lies in the provision of an effective structure for managing marine systems but leaving member states (with their own unique ways of functioning) free to decide specific details of how each step should be carried out. The ecosystem-based management system could also serve to facilitate communication, dissemination, and practicing of the ecosystem approach.

\section{DISCUSSION}

The need for reconciliation of maritime economic activities with the preservation of marine ecosystems under the ecosystem approach is clearly mandated in many international policies (e.g., Canada's Oceans Act, Marine Strategy Framework Directive). Regulatory tools for ecosystem stewardship, maritime spatial planning, or integrated coastal zone management are developing around the world (Katsanevakis et al. 2011). Nevertheless, translating these high-level goals into operational objectives requires clearly defined processes and quality-management schemes.

The ecosystem approach has emerged as the dominant paradigm for managing marine ecosystems. However, the vast array of methodologies and tools formulated to assist with application of the ecosystem approach have had limited impacts on practical implementation (Curtin and Prellezo 2010). In order to bridge the gulf between theory and practice, while maintaining the principles of the ecosystem approach, we have described a standard system, the ecosystem-based management system, to manage marine ecosystems. The ecosystem-based management system is based on international standards and written in a language understandable to managers; it is adapted from the welltested and widely used environmental management system but incorporates the unique aspects of the ecosystem approach. The ecosystem-based management system introduces a common language and a common set of procedures, and it identifies essential tools that can be useful for facilitating implementation and capacity building. The ecosystem-based management system is a crucial step forward for the practical implementation of the ecosystem approach because it integrates the assessment piece into a managerial cycle where the information and participative pillars are focused on the management decisions instead of the management risks described by the assessment.

Programs designed to deliver the ecosystem approach should operate at appropriate scales dictated by the ecological and social boundaries of particular systems (Atkins et al. 2011, Elliott 2011). However the social structures and jurisdictions of particular competent authorities are often not aligned with ecological 
boundaries. The ecosystem-based management system is scalable and its structures can be adopted for any program of measures, from initiatives on the regional sea scale envisaged by the Marine Strategy Framework Directive and supported by international cooperative agreements (OSPAR, HELCOM, UNEP-MAP, and Black Sea Commission) to the federal and provincial programs underway in Canada. The clear definition of structures, roles. and responsibilities, combined with the emphasis on participation, provide a coherent and practical framework for application at any relevant scale. In Europe the ecosystem-based management system could be used to integrate the Marine Strategy Framework Directive and the marine spatial planning-ICM proposal under a single, comprehensive management framework that could be standardized in the region and serve as a template worldwide.

While the managerial pillar of the ecosystem-based management system provides a structure and quality-control process for the implementation of the ecosystem approach, the plans and measures implemented as part of the ecosystem-based management system need to be informed by data. In the ecosystem-based management system this requirement is met by the information pillar. For Europe's seas at least, data on driver, pressure, and state are relatively well developed and readily available at the international level (i.e., through the International Council for the Exploration of the Sea (ICES)) and at the centralized European level (i.e., through the European Commission) and to some extent on a regional sea level (e.g., through Baltic Marine Environment Protection Commission Helsinki Commission (HELCOM)). Critically for the ecosystem approach, reliable spatial information linking environmental state changes to changes in human welfare (ecosystem services data) are in short supply (O'Higgins and Gilbert 2013), a factor recognized internationally as an impediment to ecosystem approach implementation (O'Higgins et al. 2010, Jordan et al. 2012, Raheem et al. 2012).

One of the main characteristics of the ecosystem approach is its multisectorial approach (Tallis 2010); the participatory pillar of the ecosystem-based management system is designed to incorporate multistakeholder perspectives into the development of goals or visions. Structures to facilitate multisectorial inputs are developing (e.g., the Regional Advisory Councils of ICES) but there are many different marine sectors and interest groups, each with competing objectives for the use of marine resources and ecosystem services. Public ignorance of the marine environment (Rose et al. 2008, Potts et al. 2011) as well as scientific uncertainty about ecosystem function combined with the compromises inherent in setting targets through consensus, have the potential to dilute any vision for environmental quality. To this end, public education and outreach, as well as further research into ecosystem functioning, are required.

The participatory mapping initiatives which are beginning to emerge (Scholz et al. 2004, St. Martin and Hall-Arber 2008, Alexander et al. 2012) have the potential to address some of the information needs regarding ecosystem state and they have the potential to enhance the levels of participation around the ecosystem services concept. Approaches such as the use of MultiCriteria Analysis can also be used to resolve spatial conflicts and build consensus toward a vision for the marine environment (Alexander et al. 2012) thereby providing inputs to both the participatory and information pillars of the ecosystem-based management system.

\section{CONCLUDING REMARKS}

Our central argument is that despite academic attention, the practical uptake of the ecosystem approach has been slow. In order for the ecosystem approach to be widely adopted in management, a standardized stepwise process is needed so that environmental managers can ensure consistency in the development of management measures that address the aspirations of the stakeholders and meet legislative and regulatory requirements. The ecosystem-based management system is a stepwise process that combines environmental quality- and riskmanagement system theory with the ecosystem approach principles. Based on existing management practices and standards, it presents a viable, systematic means of implementing the ecosystem approach. The tools contained within the ecosystem-based management system are, to a certain extent, already available or rapidly developing. Regardless of the specific legislative obligations under any particular jurisdiction, the ecosystem-based management system can provide a practical basis for ecosystem approach implementation.

The ecosystem-based management system is designed to be a standard methodology to assist in the management of coastal and marine environments by introducing a common set of tools and procedures and a common language that can be useful for facilitating knowledge transfer and capacity building. The main advantages of the ecosystem-based management system are: (a) scalability: the ecosystem-based management system can be hierarchically introduced at different spatial scales, thus facilitating nested approaches; (b) quality assurance: the ecosystem-based management system is a quality-assurance tool by itself - the process verifies and determines whether the goals for the system meet expectations and time frames, and (c) visiondriven process: GEnS (or other type of desired vision) drives the tool, making it necessary to reach a societal consensus for desired future conditions.

The ecosystem-based management system has a three-pillar structure comprised of managerial, information, and participatory pillars which can facilitate adaptive management and continuous improvement for meeting targets under the ecosystem approach. The managerial pillar follows wellestablished and successful techniques for management and quality assurance and adapts them to the more recent concepts of the ecosystem approach. As noted in the cases of Canada and Europe, the tools and techniques that contribute to the information and participatory pillars are already emerging, but a formalized structure such as that of the ecosystem-based management system can assure their effective uptake and utilization on a practical basis.

The standard operating practices proposed here have the potential to facilitate the implementation of the Marine Strategy Framework Directive and other ecosystem approach policies. They provide a structured and intercomparable process that bridges the theory and concepts of the ecosystem approach to management practices. The ecosystem-based management system uses terminology that is closer to policy and management disciplines, compared to the terminology used in the natural sciences in general, to alleviate the problems of jargon and narrow 
the gulf between the theory and practice of the ecosystem approach. One of the things that has to be understood by academia is that any management plan will always have to be implementable by existing legislative and regulatory frameworks. Within a national or an international context, agreements can identify common or complementary ecosystem objectives for planning in order to address broader scale issues within the ecosystem boundaries. Ecosystem science or stakeholder engagement contributes valuable knowledge and considerations to the planning process. The implementation, however, will depend on the legislative and regulatory frameworks of the management area. Other regulatory mandate management programs in the fields of health and engineering have operated under such standards and guidelines for some time.

Modern marine management needs to be carried out in an integrated way that considers the entire ecosystem, including humans. The ecosystem-based management system proposes a standardized system for facilitating the practice of marine management as well as facilitating capacity building.

Responses to this article can be read online at: http://www.ecologyandsociety.org/issues/responses. $\mathrm{php} / 7055$

\section{Acknowledgments:}

This work was carried out within the framework of the EU-FP7 project Knowledge-Based Sustainable Management for Europe's Seas (KnowSeas, grant contract 226675) which aimed to develop a comprehensive scientific knowledge base and provide practical guidance for the application of the ecosystem approach to the sustainable development of Europe's regional seas. We want to thank our colleagues in the KnowSeas project for discussions about the ecosystem-based management system (EBMS), and we thank Fisheries and Oceans Canada for their support. We thank all participants in the International Council for the Exploration of the Sea's (ICES) workshop on Quality Assurance of Marine Spatial Planning Processes (WKQAMSP), which took place in February 2010 in Halifax, Nova Scotia, Canada. We are also thankful for the fruitful comments of two anonymous reviewers. Readers interested in the practical matters of the EBMS are invited to contact the authors andlor visit the web platform of the KnowSeas project (www.msfd.eu).

\section{LITERATURE CITED}

Alexander, K. A., R. Janssen, G. Arciniegas, T. G. O'Higgins, T. Eikelboom, and T. A. Wilding. 2012. Interactive marine spatial planning: siting tidal energy arrays around the Mull of Kintyre. $P L o S \quad O N E$ 7(1):e30031. http://dx.doi.org/10.1371/journal. pone. 0030031

Arkema, K. K., S. C. Abramson, and B. M. Dewsbury. 2006. Marine ecosystem-based management: from characterization to implementation. Frontiers in the Ecology and the Environment 4:523-532. http://dx.doi.org/10.1890/1540-9295(2006)4[525:MEMFCT] 2.0. $\mathrm{CO} ; 2$

Aswani, S., P. Christie, N. A. Muthiga, R. Mahon, J. H. Primavera, L. A. Cramer, E. B. Barbier, E. F. Granek, C. J. Kennedy, E.
Wolanski, and S. Hacker. 2012. The way forward with ecosystembased management in tropical contexts: reconciling with existing management systems. Marine Policy 36:1-10. http://dx.doi. org/10.1016/j.marpol.2011.02.014

Atkins, J. P., D. Burdon, M. Elliott, and A. J. Gregory 2011. Management of the marine environment: integrating ecosystem services and societal benefits with the DPSIR framework in a systems approach. Marine Pollution Bulletin 62:215-226. http:// dx.doi.org/10.1016/j.marpolbul.2010.12.012

Bainbridge, J. M., T. Potts, and T. G. O'Higgins. 2011. Rapid policy network mapping: a new method for understanding governance structures for implementation of marine environmental policy. PLoS ONE 6(10):e26149. http://dx.doi.org/10.1371/journal. pone.0026149

Balvanera, P., G. C. Daily, P. R. Ehrlich, H. Ricketts, S. A. Bailey, S. Kark, C. Kremen, and H. Pereira. 2001. Conserving biodiversity and ecosystem services. Science 291:2047. http://dx. doi.org/10.1126/science.291.5511.2047

Borja, A., S. B. Bricker, D. M. Dauer, N. T. Demetriades, J. C. Ferreira, A. T. Forbes, P. Hutchings, X. Jia, R. Kenchington, J. C. Marques, and C. Zhu. 2008. Overview of integrative tools and methods in assessing ecological integrity in estuarine and coastal systems worldwide. Marine Pollution Bulletin 56:1519-1537. http://dx.doi.org/10.1016/j.marpolbul.2008.07.005

Borja, A., M. Elliott, J. A. Andersen, A. C. Cardoso, J. Carstensen, J. G. Ferreira, A. S. Heiskanen, J. C. Marques, J. M. Neto, H. Teixeira, L. Uusitalo, M. C. Uyarra, and N. Zampoukas. 2013. Good environmental status of marine ecosystems: what is it and how do we know we have attained it? Marine Pollution Bulletin 76:16-27.

Borja, A., M. Elliott, A. C. Carstensen, A. S. Heiskannen, and A. S. van de Bund. 2010. Marine management-towards an integrated implementation of the European Marine Strategy Framework and the Water Framework Directive. Marine Pollution Bulletin 60:2175-2186. http://dx.doi.org/10.1016/j. marpolbul.2010.09.026

Canadian Environmental Assessment Act, 2012 (S.C. 2012, c. 19, s. 52). Government of Canada, Ottawa, Ontario, Canada. [online] URL: http://laws-lois.justice.gc.ca/eng/acts/C-15.21/page-1.html

Cinnirella, S., D. March, T. G. O’Higgins, C. Murciano, R. Sardà, J. Albaigés, and N. Pirrone. 2012. A multidisciplinary spatial data infrastructure for the Mediterranean to support implementation of the Marine Strategy Framework Directive. International Journal of Spatial Data Infrastructures Research 7:323-352.

Cognetti, G., and F. Maltagliati. 2010. Ecosystems service provision: an operational way for marine biodiversity conservation and management. Marine Pollution Bulletin 60:1916-1923. http://dx.doi.org/10.1016/j.marpolbul.2010.09.017

Cooper, P. 2013. Socio-ecological accounting: DPSWR, a modified DPSIR framework, and its application to marine ecosystems. Ecological Economics 94:106-115. http://dx.doi. org/10.1016/j.ecolecon.2013.07.010

Cormier, R., A. Kannen, I. Davies, R. Sardá, and A. Diedrich. 2010. Policy fragmentation implications in ecosystem-based management in practice. Working Paper. Proceedings of the ICES 
Annual Science Conference, ICES Annual Science Conference, Nantes, France, 20 to 24 September 2010.

Cormier, R., A. Kannen, M. E. P. Hall, and I. M. Davies. 2013. Marine and coastal ecosystem-based risk management handbook. ICES Cooperative Research Report No. 317. International Council for the Exploration of the Sea (ICES), Copenhagen, Denmark.

Curtin, R., and R. Prellezo. 2010. Understanding marine ecosystem based management: a literature review. Marine Policy 34:821-830. http://dx.doi.org/10.1016/j.marpol.2010.01.003

Deming, E. W. 1986. Out of the crisis. Center for Advanced Engineering Study, Massachusetts Institute of Technology, Boston, Massachusetts, USA.

deReynier, Y. L., P. S. Levin, and H. L. Shoji. 2010. Bringing stakeholders, scientists and managers together through an integrated ecosystem assessment process. Marine Policy 34:534-540. http://dx.doi.org/10.1016/j.marpol.2009.10.010

Douvere, F. 2008. The importance of marine spatial planning in advancing ecosystem-based sea use management. Marine Policy 32:762-771. http://dx.doi.org/10.1016/j.marpol.2008.03.021

Douvere, F., and C. N. Ehler. 2009. New perspectives on sea use management: initial findings from European experience with marine spatial planning. Journal of Environmental Management 90:77-88. http://dx.doi.org/10.1016/j.jenvman.2008.07.004

Ehler, C., and F. Douvere. 2009. Marine spatial planning: a stepby-step approach toward ecosystem-based management. Intergovernmental Oceanographic Commission Manual and Guides No. 53, ICAM Dossier No. 6. Intergovernmental Oceanographic Commission and Man and the Biosphere Programme, UNESCO, Paris, France.

Elliott, M. 2011. Marine science and management means tackling exogenic unmanaged pressures and endogenic managed pressures - a numbered guide. Marine Pollution Bulletin 62:651-655. http:// dx.doi.org/10.1016/j.marpolbul.2010.11.033

Espinosa-Romero, M. J., K. M. A. Chan, T. McDaniels, and D. M. Dalmer. 2011. Structuring decision-making for ecosystembased management. Marine Policy 35:575-583. http://dx.doi. org/10.1016/j.marpol.2011.01.019

European Commission. 2007. Directive 2007/02/EC of the European Parliament and of the Council as of 14 March 2007 establishing an Infrastructure for Spatial Information in the European Community (INSPIRE). Official Journal of the European Union L108(50):1-14.

European Commission. 2008. Directive 2008/56/EC of the European Parliament and of the Council of 17 June 2008 establishing a framework for community action in the field of marine environmental policy (Marine Strategy Framework Directive). Official Journal of the European Union L164 (51):19-40.

European Commission. 2009. Green paper: reform of the common fisheries policy. COM(2009) 163 final. Commission of the European Communities, Brussels, Belgium.

Farmer, A., L. Mee. O. Langmead, P. Cooper, A. Kannen, P. Kershaw, and V. Cherrier. 2012. The ecosystem approach in marine management. Policy Brief No. 1. EU FP7 KNOWSEAS Project. KnowSeas (Knowledge-Based Sustainable Management for Europe's Seas), Scottish Association for Marine Science (SAMS), Oban, Scotland.

Fisheries and Oceans Canada. 2002. Canada's oceans strategy: our oceans, our future - policy and operational framework for integrated management of estuarine, coastal and marine environments in Canada. Oceans Directorate, Fisheries and Oceans Canada, Ottawa, Ontario, Canada.

GESAMP. 1996. The contributions of science to integrated coastal management. GESAMP Reports and Studies No. 61. Joint Group of Experts on the Scientific Aspects of Marine Environmental Protection (GESAMP), Food and Agriculture Organization of the United Nations, Rome, Italy.

Global Ocean Commission. 2014. From decline to recovery: a rescue package for the global ocean. Global Ocean Commission, Oxford, UK.

Government of the Netherlands and Government of Malawi. 1998. Report of the workshop on the ecosystem approach, Lilongwe, Malawi, 26-28 January 1998. Conference of the Parties to the Convention on Biological Diversity. Fourth meeting, Bratislava, Slovakia, 4 to 15 May 1998, Item 13 of the provisional agenda (review of the operations of the Convention: longer-term programme of work). UNEP/CBD/COP/4/Inf.9. [online] URL: https://www.cbd.int/doc/meetings/cop/cop-04/information/cop-04inf-09-en.pdf

International Organization for Standardization (ISO). 2004. ISO 14001:2004, environmental management systems - requirements with guidance for use. Geneva, Switzerland.

International Organization for Standardization (ISO). 2009a. ISO 31000:2009, risk management—principles and guidelines. Geneva, Switzerland.

International Organization for Standardization (ISO). 2009b. ISO Guide 73:2009, risk management-vocabulary. Geneva, Switzerland.

International Organization for Standardization (ISO). 2009c. IEC 31010:2009, risk management_risk assessment techniques. Geneva, Switzerland.

Jessen, S. 2011. A review of Canada's implementation of the Oceans Act since 1997-from leader to follower? Coastal Management 39:20-56.

Jordan, S., T. G. O'Higgins, and J. A. Dittmar. 2012. Ecosystem services of coastal habitats and fisheries: multiscale ecological and economic models in support of ecosystem-based management. Marine and Coastal Fisheries: Dynamics Management and Ecosystem Science 4:573-586. http://dx.doi. org/10.1080/19425120.2012.703162

Juda, L. 2007. The European Union and ocean use management: the marine strategy and the maritime policy. Ocean Development \& International Law 38: 259-282. http://dx.doi.org/10.1080/0090$\underline{8320701530466}$

Katsanevakis, S., V. Stelzenmüller, A. South, K. Sørensen, P. J. S. Jones, S. Kerr, F. Badalamenti, C. Anagnostou, P. Breen, G. Chust, G. D’Anna, M. Dujin, T. Filatova, F. Fiorentino, H. Hulsman, K. Johnson, A. P. Karageorgis, I. Kröncke, S. Mirto, C. Pipitone, 
S. Portelli, W. Qiu, H. Reiss, D. Sakellariou, M. Salomidi, L. van Hool, V. Vassilopoulou, T. Vega Fernández, S. Vöge, A. Weber, A. Zenetos, and R. ter Hofstede. 2011. Ecosystem-based marine spatial management: review of concepts, policies, tools and critical issues. Ocean \& Coastal Management 54:807-820.

MacDiarmid, S. C. 1997. Risk analysis, international trade, and animal health. Pages 377-387 in V. Molak, editor. Fundamentals of risk analysis and risk management. CRC Lewis Publications, Boca Raton, Florida, USA. http://dx.doi.org/10.1201/9781439821978. $\underline{\operatorname{ch} 4.4}$

McLeod, K. L., and H. M. Leslie (editors). 2009. Ecosystembased management for the oceans. Island Press, Washington, D. C., USA.

McLeod, K. L., J. Lubchenco, S. R. Palumbi, and A. A. Rosenberg. 2005. Scientific consensus statement on marine ecosystem-based management. Prepared by scientists and policy experts to provide information about coasts and oceans to U.S. policy-makers. [online] URL: http://www.compassonline.org/ sites/all/files/document files/EBM Consensus Statement v12.pdf

Measham, T., and S. Lockie. 2012. Risk and social theory in environmental management. CSIRO Publications, Collingwood, Australia.

Mee, L. D., R. Jefferson, D. d'A. Laffoley, and M. Elliott. 2008. How good is good? Human values and Europe's proposed Marine Strategy Directive. Marine Pollution Bulletin 56:187-204. http:// dx.doi.org/10.1016/j.marpolbul.2007.09.038

Mengerink, K., A. Schempp, and J. Austin. 2009. Ocean and coastal ecosystem-based management: implementation handbook. Environmental Law Institute, Washington, D.C., USA. [online] URL: http://www.eli.org/sites/default/files/eli-pubs/d19 03.pdf

Oceans Act (S.C. 1996, c. 31). Government of Canada, Ottawa, Ontario, Canada. [online] URL: http://laws-lois.justice.gc.ca/eng/ acts/O-2.4/page-1.html

O’Higgins, T. G., S. P. Ferraro, D. D. Dantin, S. J. Jordan, and M. M. Chintala. 2010. Habitat scale mapping of fisheries ecosystem service values in estuaries. Ecology and Society 15(4):7. [online] URL: http://www.ecologyandsociety.org/vol15/iss4/art7

O'Higgins, T. G., and A. J. Gilbert. 2013. Embedding ecosystem services into the Marine Strategy Framework Directive: illustrated by eutrophication in the North Sea. Estuarine Coastal and Shelf Science 140(March):146-152. http://dx.doi.org/10.1016/ j.ecss.2013.10.005

Olsen, S. B., G. G. Page, and E. Ochoa. 2009. The analysis of governance responses to ecosystem change: a handbook for assembling a baseline. LOICZ Reports and Studies No. 34. GKSS Research Center, Geesthacht, Germany.

Ounanian, K., D. J. Raakjaer, and P. Ramirez-Monsalve. 2012. On unequal footing: stakeholder perspectives on the marine strategy framework directive as a mechanism of the ecosystembased approach to marine management. Marine Policy 36:658-666. http://dx.doi.org/10.1016/j.marpol.2011.10.008

Potts, T., T. G. O’Higgins, L. Mee, and C. Pita. 2011. Public perceptions of Europe's seas: a policy brief. Policy Brief No. 2. EU FP7 KnowSeas Project. KnowSeas (Knowledge-Based Sustainable Management for Europe's Seas), Scottish Association for Marine Science (SAMS), Oban, Scotland.
Raheem, N., S. Colt, E. Fleishman, J. Talberth, P. Swedeen, K. J. Boyle, M. Rudd, R. D. Lopez, D. Crocker, D. Bohan, T. G. O'Higgins, G. Willer, and R. M. Boumans. 2012. Application of non-market valuation to California's coastal policy decisions. Marine Policy 36:1166-1171. http://dx.doi.org/10.1016/j. marpol.2012.01.005

Rice, J., V. Trujillo, S. Jennings, K. Hylland, O. Hagstrom, A. Astudillo, A., and J. N. Jensen. 2005. Guidance on the application of the ecosystem approach to management of human activities in the European marine environment. ICES Cooperative Research Report 273. International Council for the Exploration of the Sea (ICES), Copenhagen, Denmark.

Rose, C., P. Dade, and J. Scott. 2008. Qualitative and quantitative research into public engagement with the undersea landscape in England. Natural England Research Reports NERR019. Natural England, Kendal, Cumbria, UK.

Roxburgh, T. (coordinating author). 2012. Towards sustainability in the Celtic Sea: a guide to implementing the ecosystem approach through the Marine Strategy Framework Directive. PISCES (Partnerships Involving Stakeholders in the Celtic Sea Ecosystem). WWF-UK, Surrey, UK.

Ruckelshaus, M., T. Klinger, N. Knowlton, and D. P. deMaster. 2008. Marine ecosystem-based management in practice: scientific and governance challenges. BioScience 58:53-63. http://dx.doi. org/10.1641/B580110

Sanó, M. 2009. A systems approach to identify indicators for integrated coastal zone management. Ph.D. dissertation. Department of Water Science and Technology, Civil Engineering School, University of Cantabria, Santander, Cantabria, Spain.

Scholz, A., K. Bonzon, R. Fujita, N. Benjamin, N. Woodling, P. Black, and C. Steinback. 2004. Participatory socioeconomic analysis: drawing on fishermen's knowledge for marine protected area planning in California. Marine Policy 28:335-349. http://dx. doi.org/10.1016/j.marpol.2003.09.003

Shepherd, G., editor. 2008. The ecosystem approach: learning from experience. International Union for Conservation of Nature (IUCN), Gland, Switzerland. http://dx.doi.org/10.2305/IUCN. CH.2008.CEM.5.en

St. Martin, K., and M. Hall-Arber. 2008. The missing layer: geotechnologies, communities, and implications for marine spatial planning. Marine Policy 32:779-786. http://dx.doi.org/10.1016/j. marpol.2008.03.015

Tallis, H., P. S. Levin, M. Ruckelhaus, S. E. Lester, K. L. McLeod, D. L. Fluharty, and B. S. Halpern. 2010. The many faces of ecosystem-based management: making the process work today in real places. Marine Policy 34(2):340-348. http://dx.doi. org/10.1016/j.marpol.2009.08.003

Treasury Board of Canada Secretariat. 2004. Integrated risk management implementation guide. Cat. No. BT22-92/2004. Treasury Board of Canada Secretariat, Ottawa, Ontario, Canada.

van Leeuwen, J., L. van Hoof, and J. van Tatenhove. 2012. Institutional ambiguity in implementing the European Union Marine Strategy Framework Directive. Marine Policy 36:636-643. http://dx.doi.org/10.1016/j.marpol.2011.10.007 